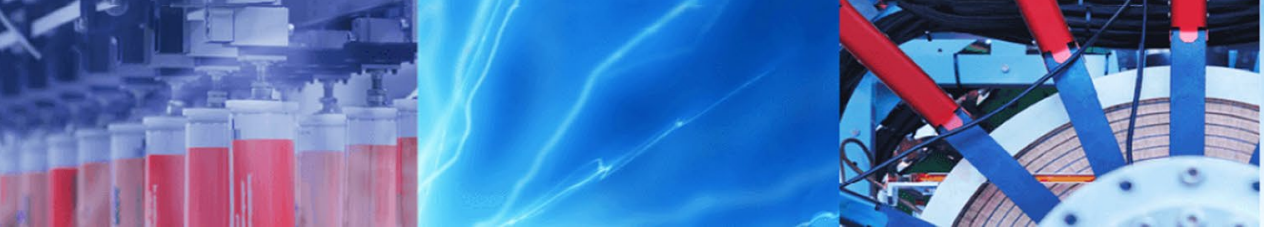

Research Article

\title{
Green synthesis of iron oxide nanoparticles using Hibiscus rosa-sinensis for fortifying wheat biscuits
}

\author{
Sirajunnisa Abdul Razack ${ }^{1,2}$ (1) $\cdot$ Abishek Suresh $^{3} \cdot$ Sanjay Sriram $^{3} \cdot$ Geethalakshmi Ramakrishnan $^{1}$. \\ Shanmugavel Sadanandham ${ }^{1} \cdot$ Manivasagan Veerasamy $^{3} \cdot$ Ramesh Babu Nagalamadaka $^{3}$. \\ Renganathan Sahadevan ${ }^{1}$
}

Received: 22 November 2019 / Accepted: 10 March 2020 / Published online: 15 April 2020

(c) Springer Nature Switzerland AG 2020

\begin{abstract}
The present investigation is an attempt on synthesising iron oxide nanoparticles through greener mode using the petal extracts of Hibiscus rosa-sinensis and utilising them as fortificants in wheat biscuits. Ferric and ferrous chloride at a concentration of $0.025 \mathrm{M}$ and at a ratio of 2:1 was used as the metal precursors and the extract was served as the reducing agent. Synthesised iron oxide nanoparticles were characterised using UV-visible spectroscopy, X-ray diffraction (XRD), FTIR spectroscopy and scanning electron microscopy (SEM). The analyses confirmed that the formed particles were nano sized and the crystallite size was found to be $6.16 \mathrm{~nm}$ through XRD studies. The formed nanoparticles were observed from SEM analysis to be spinel shaped with an average particle size of $65 \mathrm{~nm}$. Biscuits were fortified with iron oxide nanoparticles which were later studied for physical and proximate analyses. The inductively coupled plasma optical emission spectroscopy studies revealed that the iron content was higher in fortified biscuits than that in control. Microbial analysis for 30 days indicated that the fortified biscuits could have a longer shelf life. In brief, the first report on use of iron oxide nanoparticles successfully suggested that their use as fortificants in food and could be prescribed for malnourished, iron deficit or anaemic patients.
\end{abstract}

Keywords Food products · Nanofabrication · Nanobactericidal · Hibiscus rosa-sinensis

\section{Introduction}

Food fortification has been commercialized as a major technique to retard deficiency of certain vitamins like vitamin A, vitamin B1 (thiamine), vitamin B2 (riboflavin) and vitamin B6 (niacin), iodine and iron [1]. Iron deficiency is the most common nutritional cause of anaemia in infants and women which is predominant in India. Iron deficiency can bring in harmful effect on learning and neural systems even with normal haemoglobin levels despite the confounding impact of socioeconomic factors. If iron deficiency is not checked at infancy, it might lead to cognitive and behavioural disfunctioning in the later stages of life. Then a major part of the population would live with iron deficiency [2]. Commonly used iron fortificants are ferrous sulphate, ferrous fumarate, ferrous succinate, ferrous lactate, ferrous gluconate, elemental iron, ferric ammonium citrate, sodium iron EDTA and ferric saccharate [1]. Iron fortification, in recent years, could be done by introducing iron and iron oxide nanoparticles in foodstuffs. Due to no change in character of fortified food, product stability and large bioavailability, they could also impart good health by increasing haemoglobin levels and nutrition [3-6]. Ice cream was enriched with alginate nanoparticles including

\footnotetext{
$\triangle$ Renganathan Sahadevan, rengsah@rediffmail.com | ${ }^{1}$ Centre for Biotechnology, Anna University, Chennai, Tamilnadu 600025, India. ${ }^{2}$ Department of Biochemistry, Faculty of Science, Chulalongkorn University, Bangkok 10330, Thailand. ${ }^{3}$ Adhiyamaan College of Engineering, Hosur, Tamilnadu 635109, India.
} 
Fe and $\mathrm{Zn}$ salts [7]. In sausages, iron was fortified as iron oxide nanoparticles in the form of colorants; in USA, for people preferring packed foods consumed around $450 \mu \mathrm{g} /$ day [8]. Recent reports have revealed that food fortified using iron nanoparticles were safe through in vivo and invitro experiments [6].

Iron, especially iron oxide or magnetite $\left(\mathrm{Fe}_{3} \mathrm{O}_{4}\right)$, nanoparticles are one of the most significant set of inorganic nanoparticles due to their super paramagnetism and easy separation [9]. Particle size to nanoscale, when reduced, exhibit increase in absorption when utilised for fortifying foods [10]. Magnetic nanoparticles with the desired size and shape have remained a huge challenge for nanotechnologists [11]. Various progressive techniques like sol gel, sonochemical, thermolysis of precursors, hydrolysis, co precipitation, reverse micelles, hydrothermal and thermal decomposition have been used in iron oxide nanoparticles [12]. Chemical synthesis has been the most common route for nanopreparations, especially the co precipitation technique of iron salts. Due to major limitations in chemical route of synthesis like low dispersion in solvents, wider particle size distribution, difference in particle size uniformity causing aggregation of particles led to an immense interest in green synthesis using plants and other biological systems. The biological synthesis using inactivated plant tissue, plant extract [13], exudates [14] and other parts of living plants are certain modern alternatives. Hibiscus is widely used in India as an ornamental plant and as a medicine in Indian system. The plant is a potent antifungal agent and has anticancer activity. The leaves and flowers of Hibiscus rosa-sinensis are used as an antiseptic and antidiabetic [15]. Species of Hibiscus like syriacus and rosa-sinensis are large resources of phytochemicals like flavanoids, phenolics and tannins, macromolecules like proteins, carbohydrates, trace elements, phosphorus, calcium and iron [16].

The present investigation is a study performed to assess the enhancement of iron concentration in wheat biscuits by fortifying with iron nanoparticles synthesized using the aqueous extract of the petals of Hibiscus rosa-sinensis. Scanty reports are available for fortification of foodstuff using iron and this is the first report on fortifying biscuits with iron oxide nanoparticles.

\section{Methodology}

\subsection{Extract preparation}

Hibiscus flowers were collected from a local flower market, Chennai, Tamilnadu, India $\left(13.0692^{\circ} \mathrm{N}, 80.1914^{\circ} \mathrm{E}\right)$. The petals were separated from stamens and calices and left to shade dry until they became brittle. The dried petals were ground in a blender to a fine powder which was collected in an air tight container and stored at $4{ }^{\circ} \mathrm{C}$ for further use and analysis. A quantity of $2 \mathrm{~g}$ of hibiscus petal powder was added to $100 \mathrm{~mL}$ of distilled water in a $250 \mathrm{~mL}$ Erlenmeyer flask and heated for $1 \mathrm{~h}$ at $60^{\circ} \mathrm{C}$. The mixture was filtered to remove debris using Whatmann No.1 filter paper. The filtrate was centrifuged at $7000 \mathrm{rpm}$ for $15 \mathrm{~min}$ to remove fine debris. The prepared extract was then used as the reducing agent in nanoparticle synthesis.

\subsection{Synthesis of iron oxide nanoparticles}

Magnetite $\left(\mathrm{Fe}_{3} \mathrm{O}_{4}\right)$ nanoparticles were prepared using ferric chloride as the precursor and petal extract as the reducing agent. A volume of $100 \mathrm{~mL}$ of $25 \mathrm{mM}$ precursor solution of ferric chloride and $25 \mathrm{mM}$ of ferrous chloride solution at a ratio of 2:1 was taken in an Erlenmeyer flask and an equal volume of extract was added to the solution. The solution was mixed well for an hour at $200 \mathrm{rpm}$ at room temperature for better reaction, though instantaneous precipitation could be observed. Then the solution was centrifuged at $7000 \mathrm{rpm}$ for $15 \mathrm{~min}$, the pellet obtained was suspended in water and centrifuged under same conditions. The process was repeated thrice to eliminate impurities. The pellet was placed in a hot air oven at $40^{\circ} \mathrm{C}$ overnight to remove moisture and unwanted particles. The dried nanoparticle powder was placed for calcination in a muffle furnace at $400^{\circ} \mathrm{C}$ for $3 \mathrm{~h}$. Nanoparticles were collected and weighed in a vial for further characterisation and application studies.

\subsection{Nanoparticle characterisation}

\subsubsection{UV visible spectral analysis}

Preliminary confirmation of the synthesized $\mathrm{Fe}_{3} \mathrm{O}_{4}$ nanoparticle was carried out using UV Vis Spectrophotometry (Model: G10S, Thermo Fisher Scientific Ltd., USA). The sample was scanned to find out the maximum absorbance at wavelength ranging between 200 and $700 \mathrm{~nm}$.

\subsubsection{Fourier transform infrared spectroscopy analysis}

FTIR spectroscopy was performed to study the nature of surface adsorbents in nanoparticles. The technique was carried out by adding $0.5 \mathrm{mg}$ of sample with $150 \mathrm{mg}$ of $\mathrm{KBr}$. The mixture was finally pressed into discs and introduced into the sample holder to display the result as a spectrum with FTIR spectroscope scanning the samples at wavelength ranging between 8000 and $300 \mathrm{~cm}^{-1}$. 


\subsection{3 $\mathrm{X}$ ray diffraction analysis}

The crystalline size of the nanoparticle was determined using X-ray diffractometer (Xpert pro, Belgium). The size was calculated from the spectrum using Debye-Scherrer's equation.

$D=(K \lambda) \div(\beta \operatorname{Cos} \theta)$

where $\mathrm{D}$ is the particle size of the nanoparticle, $\mathrm{K}$ is the shape factor, $\lambda$ is the wavelength, $\theta$ is the Bragg's angle and $\beta$ is the line width (full width at half maximum) in radius.

\subsubsection{Scanning electron microscopy and energy dispersive $\mathrm{X}$-ray analysis (EDAX)}

Morphology of synthesized iron oxide nanoparticle was examined using scanning electron microscopy. Thin films of sample were coated on to a carbon tape and allowed to dry for $5 \mathrm{~min}$. SEM images were obtained under 30000X magnification. The SEM machine was operated at an accelerating voltage of $20 \mathrm{kV}$. To minimize the destruction of sample, low voltage was maintained. Elemental iron was checked for its presence using an EDAX attached to the SEM equipment.

\subsection{Wheat biscuit preparation (control and fortified)}

A quantity of $100 \mathrm{~g}$ of unsalted butter was added to $100 \mathrm{~g}$ of wheat flour. It was mixed well until the butter blended with the flour. Then $50 \mathrm{~g}$ of powdered sugar was added and mixed with the wheat flour mixture. The prepared dough was rolled evenly on the flour dusted rolling board. Round shaped pieces were made with biscuit cutter. The pieces were arranged on the butter coated tray. The biscuits were baked at $180^{\circ} \mathrm{C}$ for $15 \mathrm{~min}$. Control biscuits were made by the above procedure. In case of fortified biscuits, $50 \mathrm{mg}$ of iron oxide nanoparticle was added during dough preparation.

\subsection{Proximate analysis}

Proximate analysis was carried out to check various contents namely moisture, ash, crude fibre, crude fat and crude protein in the fortified biscuits. From the obtained results, total carbohydrate was determined by difference [17] as follows,

$$
\begin{aligned}
\text { Total carbohydrate }= & 100-(\% \text { moisture }+\% \text { protein } \\
& +\% \text { fat }+\% \text { ash }+\% \text { crude fibre }) .
\end{aligned}
$$

\subsubsection{Moisture content}

A quantity of $5 \mathrm{~g}$ of both control and nanoparticle incorporated biscuits were placed in hot air oven at $130{ }^{\circ} \mathrm{C}$ for $3 \mathrm{~h}$ and the percent moisture content was calculated thus,
$\%$ Moisture content $=\frac{w_{1}-w_{2}}{w_{1}} \times 100$

where $w_{1}$ weight before drying, $w_{2}$ weight after drying.

\subsubsection{Ash content}

A quantity of $5 \mathrm{~g}$ of biscuits, each of control and nanoparticle incorporated, were placed in a muffle furnace at $550^{\circ} \mathrm{C}$ for $4 \mathrm{~h}$. The ash obtained was cooled in a desiccator and weighed. The ash content was calculated using the below given formula as,

$\%$ Ash $=\frac{\text { weight of ash }}{\text { weight of sample }} \times 100$.

\subsubsection{Crude fibre}

A quantity of $2 \mathrm{~g}$ each of control and nanoparticle incorporated biscuits were placed in $20 \mathrm{~mL}$ of petroleum ether separately and heated for $30 \mathrm{~min}$. Then the solvent was discarded and the sample was dried at $40^{\circ} \mathrm{C}$ for $10 \mathrm{~min}$. The dried sample was boiled with $200 \mathrm{~mL}$ of $0.26 \mathrm{M} \mathrm{H}_{2} \mathrm{SO}_{4}$ for $30 \mathrm{~min}$. Then it was filtered with muslin cloth and washed with boiled distilled water. The samples were again boiled with $200 \mathrm{~mL}$ of $0.3 \mathrm{M} \mathrm{NaOH}$ solution for $30 \mathrm{~min}$. Then it was washed with $25 \mathrm{~mL}$ of $1.25 \% \mathrm{H}_{2} \mathrm{SO}_{4}$ solution, $50 \mathrm{~mL}$ of distilled water and $25 \mathrm{~mL}$ alcohol. The residue was removed and transferred to ashing dish (preweighed dish, $\mathrm{w}_{1}$ ). The residue was then dried for $2 \mathrm{~h}$ at $130 \pm 2^{\circ} \mathrm{C}$. It was cooled in a desiccator, weighed $\left(\mathrm{w}_{2}\right)$ and ignited at $600 \pm 15^{\circ} \mathrm{C}$ for $30 \mathrm{~min}$. It was then cooled and weighed $\left(w_{3}\right)$ [18].

$\%$ Crude fibre $=\left(\frac{\left(w_{2}-w_{1}\right)-\left(w_{3}-w_{2}\right)}{w}\right) \times 100$

\subsubsection{Crude fat}

A quantity of $5 \mathrm{~g}$ of biscuit sample was placed in a thimble which was inserted in a soxhlet extractor. A volume of $90 \mathrm{~mL}$ of petroleum ether was added to $150 \mathrm{~mL}$ round bottom flask. The extraction was performed for $6 \mathrm{~h}$. The flask was placed in an oven at $102{ }^{\circ} \mathrm{C}$ and the contents were dried until a constant weight was reached (1-2 h).

$\%$ crude fat $=\left(w_{2}-w_{1}\right) \times \frac{100}{s}$

where $w_{1}$ weight of empty flask ( $g$ ), $w_{2}$ weight of flask and extracted fat (g), S Sample weight. 


\subsubsection{Crude protein}

Protein content was determined using Kjeldahl method. $2 \mathrm{~g}$ of sample was weighed and placed in the Kjeldahl flask. $10 \mathrm{~g}$ of $\mathrm{Na}_{2} \mathrm{SO}_{4}, 0.2 \mathrm{~g}$ of $\mathrm{CuSO}_{4}$ and $25 \mathrm{~mL}$ of $\mathrm{H}_{2} \mathrm{SO}_{4}$ were added to the flask and it was heated in fume hood. After complete digestion, the flasks were cooled and distilled water was added. To the flask containing digested sample, $50 \mathrm{~mL}$ of $50 \% \mathrm{NaOH}$ was added, distilled and collected in $40 \mathrm{~mL}$ of $0.1 \mathrm{~N} \mathrm{H}_{2} \mathrm{SO}_{4}$ with $1 \mathrm{~mL}$ of methylene blue in a beaker. Titration was carried out against $0.1 \mathrm{~N} \mathrm{H}_{2} \mathrm{SO}_{4}$. The volume of acid used was recorded.

$\%$ Protein $=\frac{N \times v \times 14 \times 6.25}{w} \times 100$

where N Normality of acid used, $v$ volume of acid used, $\mathrm{w}$ weight of the sample.

\subsection{Determination of physical properties}

\subsubsection{Texture analysis}

The texture of control and fortified biscuit samples were analyzed using TA-XT2 texture analyzer (Stable Micro Systems Ltd, UK). The biscuit hardness or breaking force ( $\mathrm{g}$ ) and fracturability $(\mathrm{mm})$ or distance were obtained from force time plotwhich was obtained by applying a measurement speed of $2 \mathrm{~mm} / \mathrm{s}$ and a distance of $5 \mathrm{~mm}$.

\subsubsection{Spread ratio}

Spread is calculated as the ratio of diameter and height of wheat biscuits. Four biscuits were used for the study. Diameter in millimeter, was measured using vernier callipers by arranging them horizontally edge to edge and the average of each was used for calculation. Height was measured by arranging samples in two rows and the measurement was taken up for the study [17]. Weight of the biscuits was measured using a weighing balance and an average was considered for each set of samples.

\subsection{Confirmation of iron content through ICP-OES}

The prepared standard and sample biscuits were analysed using Inductively Coupled Plasma Optical Emission Spectroscopy (ICP-OES) (Agilent, USA) for detection and confirmation of iron content at SGS Services, Chennai, Tamilnadu, India.

\subsection{Bacterial analysis}

A microbial analysis was performed in order to check the shelf life of the prepared biscuits. Bacterial count was carried out through pour plate technique. Three control and fortified biscuits each was wrapped in aluminium foil and placed in a corrugated paper box. Samples were taken for bacterial count on 1st, 3rd, 5th, 10th, 15th, 20th, 25th and 30th days. One gram of each biscuit sample was taken and added to $100 \mathrm{~mL}$ of sterile nutrient broth, serially diluted, spread on sterile $2 \%$ nutrient agar plates and incubated for $24 \mathrm{~h}$ at $37^{\circ} \mathrm{C}$. The colony forming units (CFU/g) were calculated as the [(number of colonies $\times$ dilution factor)/ quantity of sample in grams].

\section{Results and discussion}

\subsection{Nanoparticle characterisation}

Iron oxide, magnetite $\left(\mathrm{Fe}_{3} \mathrm{O}_{4}\right)$, nanoparticles were synthesised from the petal extracts of Hibiscus rosa-sinensis. Various plants had been involved in the process of preparing magnetite in greener mode [19-21]. The petals were shade dried in order to protect the nutritive value of the plant part. In the present study, the color change of the precursor solution from red to black after adding the extract confirmed the reduction of metal salts to nanoparticles as seen in Fig. 1. The iron oxides are composed of Fe together with $\mathrm{O}$ and/or $\mathrm{OH}$. The three main forms are magnetite $\left(\mathrm{Fe}_{3} \mathrm{O}_{4}\right)$, Hematite $\left(\mathrm{Fe}_{2} \mathrm{O}_{4}\right)$ and its oxidized form maghemite $\left(\gamma-\mathrm{Fe}_{2} \mathrm{O}_{3}\right)$. Magnetite, $\mathrm{Fe}_{3} \mathrm{O}_{4}$, is a black ferromagnetic containing both $\mathrm{Fe}(\mathrm{II})$ and $\mathrm{Fe}(\mathrm{III})$. Magnetite particles' magnetic properties depend strongly on the methods used in their synthesis. Hematite, $\mathrm{Fe}_{2} \mathrm{O}_{4}$, is the oldest known iron oxide mineral and is widespread in rocks and soils. Its colour is blood red if finely divided and black or a sparkling grey if coarsely crystalline. Maghemite, $\gamma-\mathrm{Fe}_{2} \mathrm{O}_{4}$, is a red brown ferromagnetic mineral isostructural with magnetite, but with cation deficient site [22].

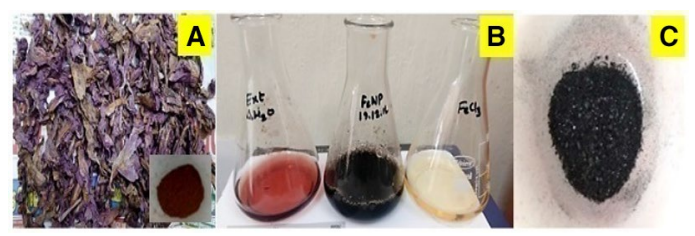

Fig. 1 Magnetite nanoparticle synthesis. a Dried hibiscus petals, inset: petal powder, b petal extract, nanoparticle solution as black precipitate and metal precursor solution, c calcined magnetite nanoparticles 
The exhibition of color by the precipitated magnetite nanoparticles was because of the excitation of molecules due to surface plasmon resonance (SPR). When the frequency of the electromagnetic field remains coherent with the electric motion, it results in effective absorption. Formation and stability of iron oxide nanoparticles in aqueous colloidal solution was confirmed by using UV-Vis spectral analysis. As in Fig. 2, maximum absorbance was found at $229 \mathrm{~nm}$. After $500 \mathrm{~nm}$, there was no absorption resulting in complete reduction and formation of iron oxide nanoparticles. The characteristic surface Plasmon resonance band of $\mathrm{Fe}_{3} \mathrm{O}_{4}$ occurs at wavelength in the range of $190-250 \mathrm{~nm}$ [23].

FTIR was performed to detect the presence of functional moieties on the iron nanoparticles. Sample was scanned in the wavelength ranging between 8000 and $300 \mathrm{~cm}^{-1}$. Figure 3a illustrated the recorded spectrum of synthesized iron oxide nanoparticle. A normal $\mathrm{OH}$ stretch was denoted by an absorption band at $3434.77 \mathrm{~cm}^{-1}$. A short intense peak at $2939.45 \mathrm{~cm}^{-1}$ was observed for $\mathrm{C}-\mathrm{H}$ methylene asymmetrical stretch $\left(>\mathrm{CH}_{2}\right)$ and a peak for $\mathrm{C}-\mathrm{H}$ methyl asymmetrical stretch $\left(-\mathrm{CH}_{3}\right)$ was found at $2978.04 \mathrm{~cm}^{-1}$. An intense absorption peak at $1670.46 \mathrm{~cm}^{-1}$ denoted the presence of imino group. $1422.01 \mathrm{~cm}^{-1}$ peak attributed to sulphate moiety. $-\mathrm{OH}$ bend of phenol or tertiary alcohol was depicted by an intense peak at $1374.91 \mathrm{~cm}^{-1}$. A sharp absorption peak at $1298.41 \mathrm{~cm}^{-1}$ demonstrated $\mathrm{OH}$ group of primary or secondary alcohol. $1117.9 \mathrm{~cm}^{-1}$ illustrated the $\mathrm{C}-\mathrm{O}-\mathrm{CN}$ stretch and $818.02 \mathrm{~cm}^{-1}$ absorption peak showed -C-O- of epoxy groups. An S-S stretch of disulfides was observed at $617.83 \mathrm{~cm}^{-1}$ and that of polysulfides was exhibited by a peak at $478.73 \mathrm{~cm}^{-1}$. The characteristic sharp absorbance peak observed at $567.94 \mathrm{~cm}^{-1}$ corresponded to $\mathrm{Fe}-\mathrm{O}$ stretching vibration for $\mathrm{Fe}_{3} \mathrm{O}_{4}$ nanoparticle in the sample [24]. The high frequency band ranging from 540 to $575 \mathrm{~cm}^{-1}$ is a characteristic band of spinel ferrite [1-s2.0-S0926860X17304052].

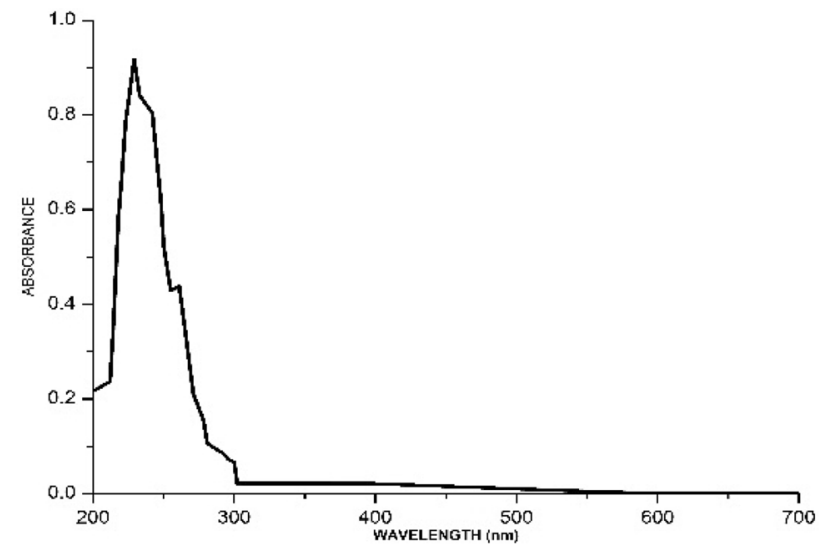

Fig. 2 UV visible spectrum of magnetite nanoparticle
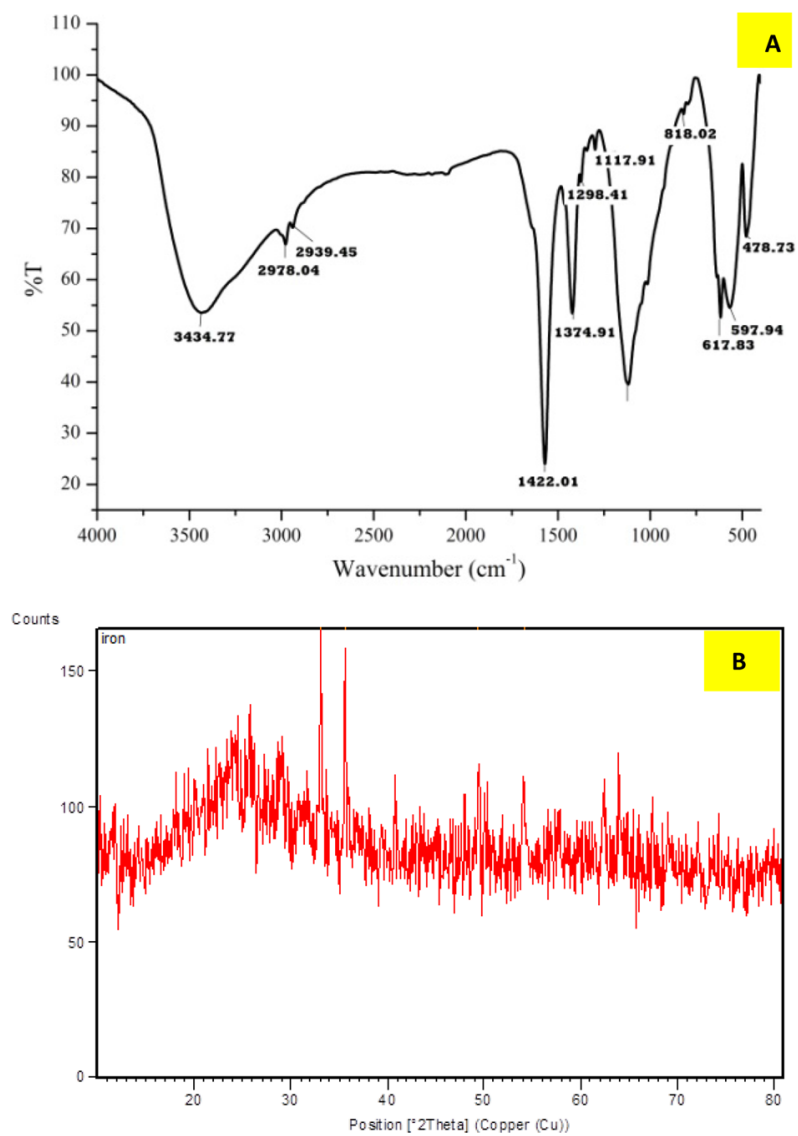

Fig. 3 a FTIR spectrum, b XRD image of magnetite nanoparticle

The phase identification and crystalline structures of the nanoparticles were characterized by XRD as it is demonstrated in Fig. 3b. The average crystallite size was found to be $6.19 \mathrm{~nm}$ using Debye-Scherrer's equation with Scherrer's constant as 0.9. From the X-ray diffraction pattern obtained, it was found that there existed diffraction peaks with $2 \theta$ values of $30^{\circ}(220), 35.5^{\circ}(311), 37.1^{\circ}(222)$, $43.4(400), 54.1^{\circ}(422), 62.47(440), 57.5^{\circ}(511)$ which were in consistence with the standard structure of magnetite (JCPDS Card No. 019-0629). The result corresponded to face cubic centered $\mathrm{Fe}_{3} \mathrm{O}_{4}$-NPs which was in complete agreement with certain previous studies [25-30]. From Fig. $3 b$, it could also be noted that the particles were both crystalline, as noted by longer and intense diffraction peaks, and amorphous as random broad peaks were visualised.

The structure of the nanoparticles was determined by Scanning electron microscopy (SEM) analysis. Figure 4 revealed the structural nature of the synthesised particles. The synthesised crystalline nanoparticles with spinel shape (cubic crystal system) were with an approximate average particle size of $65 \mathrm{~nm}$. Additionally, the particles exhibited no uniformity which might be due 
to aggregation of particles and usually occurred during biological synthesis. The size and shape of the nanoparticle depended upon the nature and concentration of the reducing agents used [31].

\subsection{Iron fortified wheat biscuits and characterisation}

Wheat biscuits were prepared in two sets, one was kept as control without the addition of magnetite nanoparticles and the other was nanoparticle fortified biscuits (Fig. 5a, b). Biscuits were chosen for the present study as they could be easily prepared, cheap and convenient with large dietary supplements like iron, calcium, fibre, B-vitamins and could impart energy to the humans. Nanoparticles provide additional advantage to the biscuits by enhancing their nutritional value [32].

The physical characterisations of the prepared biscuits were successfully analysed. The spread ratio for the control biscuit was calculated to be 2.826 from the average diameter of $52 \mathrm{~mm}$ and height of $18.4 \mathrm{~mm}$. The spread ratio of fortified biscuits was found to be 2.781 as obtained using the average diameter as $52 \mathrm{~mm}$ and height as $18.7 \mathrm{~mm}$. Spread ratio is generally used to determine the quality of flour for biscuit preparation and its ability to rise during baking [33]. The results indicated that there was no significant difference in the spread ratios before and after adding nanoparticles, indicating that the iron oxide nanoparticle did not affect the physical properties of the product, hence it could be utilised for food fortification.

Texture profile analysis is a significant characterisation to study the quality of the prepared biscuits. Hardness is defined as the force required to break the biscuit and fracturability is the ability of the sample to revert back to its original form upon relaxing the force applied. Generally, the textures of the products rely upon the type and quality of the flour used, amount of ingredients utilised

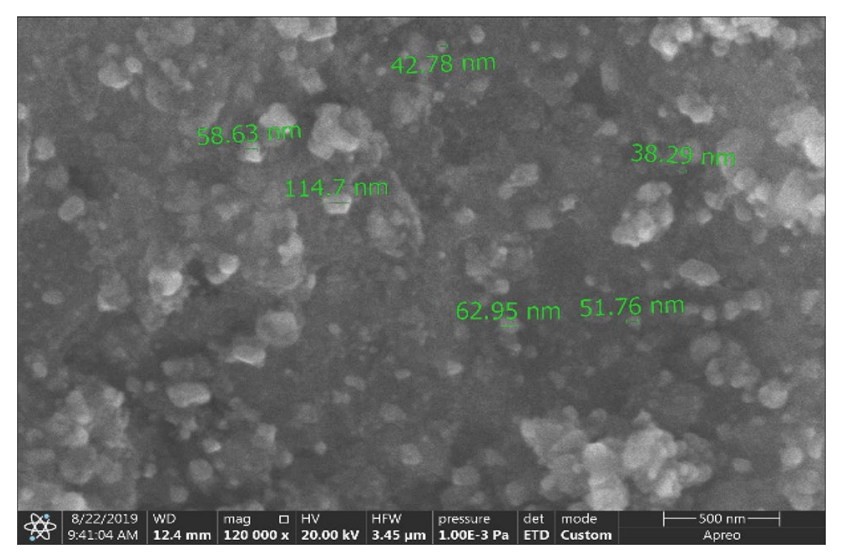

Fig. 4 SEM image of magnetite nanoparticles
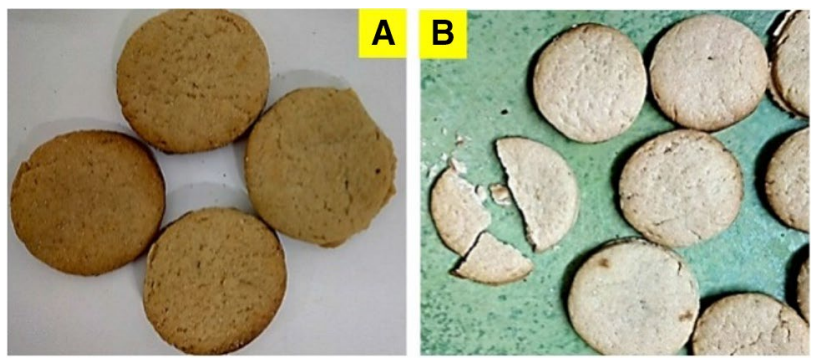

Fig. 5 Prepared $\mathbf{a}$ control and $\mathbf{b}$ fortified biscuits

and protein content present in the raw materials [34]. Figure 6 illustrated the force versus time plots for the control and fortified biscuits from which the hardness (force) and fracturability (distance) could be calculated. The plots and values suggested that the fortified biscuits were more liable to break than control biscuits, which might be due to binding efficiency of iron oxide nanoparticles in the wheat flour which has to be investigated further. Nevertheless, the difference in values did not significantly affect the storage and the wheat could be easily chewed.

\subsection{Proximate composition of biscuits}

Proximate characters such as moisture content, mineral content, protein content, crude fibre, and carbohydrate content were analysed for control wheat biscuits and fortified biscuits. Table 1 represented their proximate analyses. The study demonstrated that there were no significant changes in proximate characters of the biscuits due to fortification, nonetheless there is a slight increase in
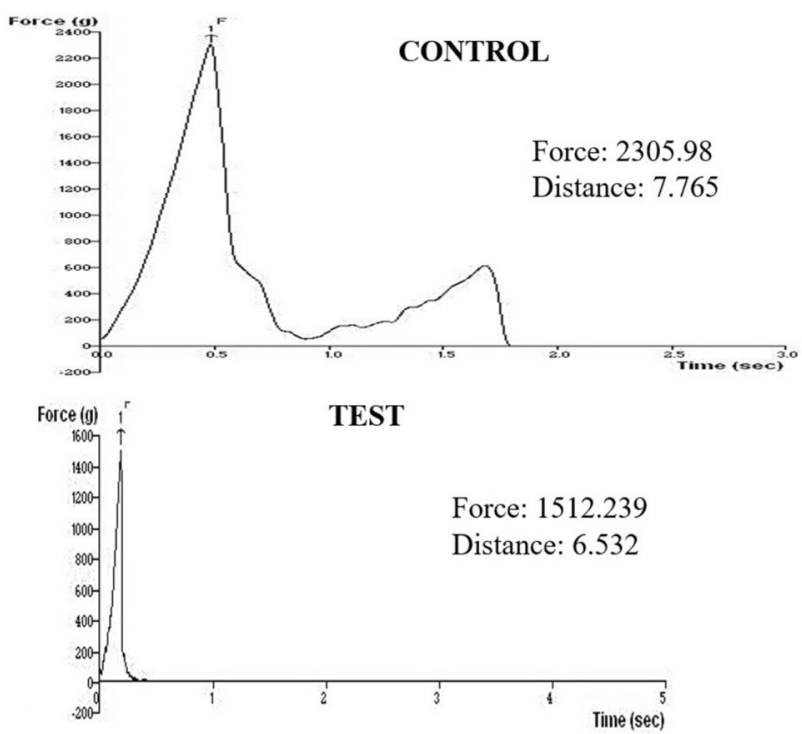

Fig. 6 Texture profile of control and fortified biscuits

\section{SN Applied Sciences}


Table 1 Proximate composition of the control and fortified biscuits

\begin{tabular}{lcc}
\hline Proximate characters (\%) & Control & Fortified \\
\hline Moisture content & 7.2 & 7.6 \\
Crude fibre & 16.0 & 16.2 \\
Crude protein & 2.6 & 2.8 \\
Crude fat & 24.6 & 24.8 \\
Ash content & 1.4 & 1.1 \\
Total carbohydrates & 51.8 & 52.5 \\
\hline
\end{tabular}

the overall chemical composition of the fortified biscuits denoting an apparent increment in chemical content of the biscuits.

\subsection{Analysis of iron content}

Inductively coupled plasma optical emission spectroscopy (ICP-OES) is specifically used for the detection of trace metals in any material. It is a type of emission spectroscopy that uses inductive coupled plasma, a type of plasma source in which energy is supplied by electric currents produced by electromagnetic radiations, to produce excited atoms and ions that emit electromagnetic radiations at wavelengths particular to the element to be tested. This analysis was therefore carried out to quantitatively analyze and confirm the presence of iron in both control and fortified biscuits. The report (see Fig. 7) eventually indicated that the fortified biscuits contained $1.5 \mathrm{mg}$ of iron/g and the control biscuits contained $0.039 \mathrm{mg}$ of iron $/ \mathrm{g}$. The fortified biscuits showed significant increase in iron content when compared to the control.

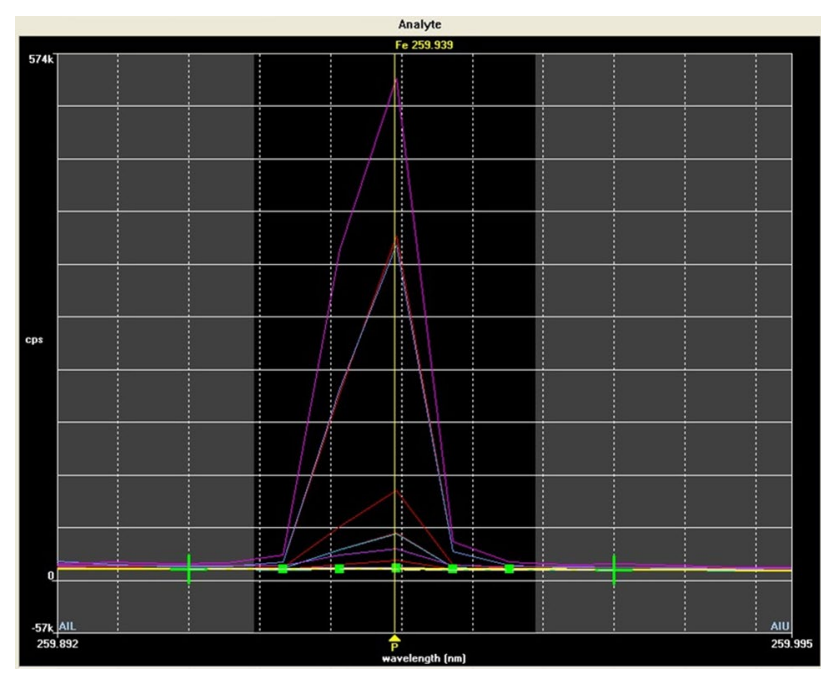

Fig. 7 ICP-OES spectrum of the biscuits prepared
Table 2 Bacterial analysis of prepared biscuits

\begin{tabular}{lll}
\hline Duration (days) & Control (CFU/g) & Fortified (CFU/g) \\
\hline 1 & Nil & Nil \\
3 & Nil & Nil \\
5 & Nil & Nil \\
7 & Nil & Nil \\
10 & $2.2 \times 10^{3}$ & Nil \\
15 & $2.9 \times 10^{3}$ & Nil \\
20 & $3.1 \times 10^{3}$ & $1.4 \times 10^{3}$ \\
25 & $3.6 \times 10^{3}$ & $2.3 \times 10^{3}$ \\
30 & $4.1 \times 10^{4}$ & $2.5 \times 10^{3}$ \\
\hline
\end{tabular}

CFU/g: colony forming units per gram of sample

\subsection{Bacteriological analysis}

The bacterial count was checked upon in order to check the duration of storage and shelf life of the biscuits. The bacteriological study was performed for a month; growth of culture was observed and calculated as CFU/g as shown in Table 2. The report indicated that the growth of bacteria was more and faster in control than that in magnetite fortified biscuits. Growth was seen from $10^{\text {th }}$ day in control biscuits $\left(2.2 \times 10^{3} \mathrm{CFU} / \mathrm{g}\right)$ which gradually increased until 30 th day $\left(4.1 \times 10^{4} \mathrm{CFU} / \mathrm{g}\right)$. On contrary, fortified biscuits were non-contaminated till 15 th day whereas the biscuits with bacterial culture was found after 15 days, $1.4 \times 10^{3} \mathrm{CFU} / \mathrm{g}$ on 20th day and slightly increased to $2.5 \times 10^{3} \mathrm{CFU} / \mathrm{g}$. The growth could be due to requirement of higher sterile conditions after processing and better packaging methods. Iron oxide nanoparticles generally could act as antimicrobial agent which might have attributed to the delayed growth. The study suggested that the overall bacterial load was low in the biscuits and thus could have a long shelf life and stability.

\section{Conclusion}

The present investigation is on enhancing the iron content in wheat biscuits using iron oxide nanoparticles as food fortificants. Iron oxide nanoparticle synthesis from non-edible sources is of great interest for research as it does not compete with food crops. Iron oxide nanoparticle was synthesised using flower petal extract of Hibiscus rosa-sinensis as a reducing agent. It was characterized through various techniques which confirmed that the particles were crystalline in nature, oblong and hexagonal shaped. The crystal size was determined to be $6.19 \mathrm{~nm}$. The SEM analysis depicted nanoparticles in various shapes like octahedral, rhombic, spherical and oblong. Physical 
and chemical composition analyses suggested that the fortification of biscuits did not interfere in the ICP-OES test report showed that the iron content of control and fortified biscuits as $0.039 \mathrm{mg} / \mathrm{g}$ and $1.5 \mathrm{mg} / \mathrm{g}$. This study proved that iron oxide nanoparticles can be used as food fortificants. The biscuits were least contaminated that suggested their longer storage capacity. Thus, future work has to be carried out to commercialize the product after completing clinical trials. Iron fortification could aid in enriching the immune response of the body as certain biscuits may contain less quantity of iron.

\section{Compliance with ethical standards}

Conflict of interest The authors declare that they have no conflicts of interest regarding this research article.

\section{References}

1. Allen LH (2006) Guidelines on food fortification with micronutrients. World Health Organization, Geneva

2. Hulthén L (2003) Iron deficiency and cognition. Scand J Nutr 47:152-156

3. Rohner F, Ernst FO, Arnold M, Hilbe M, Biebinger R, Ehrensperger F, Zimmermann MB (2007) Synthesis, characterization, and bioavailability in rats of ferric phosphate nanoparticles. J Nutr 137:614-619

4. Eilander A, Gera T, Sachdev HS et al (2009) Multiple micronutrient supplementations for improving cognitive performance in children: systematic review of randomized controlled trials. Am J Clin Nutr 91:115-130

5. Das JK, Salam RA, Kumar R et al (2013) Micronutrient fortification of food and its impact on woman and child health: a systematic review. Syst Rev 2:67

6. Zanella D, Bossi E, Gornati R et al (2017) Iron oxide nanoparticles can cross plasma membranes. Sci Rep 7:11413

7. Sharifi A, Golestan L, Baei MS (2013) Studying the enrichment of ice cream with alginate nanoparticles including $\mathrm{Fe}$ and $\mathrm{Zn}$ salts. J Nanopart 2013:754385. https://doi.org/10.1155/2013/754385

8. McClements DJ, Xiao H (2017) Is nano safe in foods? Establishing the factors impacting the gastrointestinal fate and toxicity of organic and inorganic food-grade nanoparticles. NPJ Sci Food $1: 6$

9. Kannan D, Yadav N, Ahmad S et al (2019) Pre-clinical study of iron oxide nanoparticles fortified artesunate for efficient targeting of malarial parasite. EBioMedicine 45:261-277. https://doi. org/10.1016/j.ebiom.2019.06.026

10. Von Moos LM, Schneider M, Hilty FM et al (2017) Iron phosphate nanoparticles for food fortification: biological effects in rats and human cell lines. Nanotoxicology 11:496-506

11. Kori SB, Kathole DR, Vaidya IS et al (2018) Insight to facile syntheses of iron oxide nanoparticles. Pharm Innov J 7:513-518

12. Rana P, Sharma S, Sharma R, Banerjee K (2019) Apple pectin supported superparamagnetic $\left(\gamma-\mathrm{Fe}_{2} \mathrm{O}_{3}\right)$ maghemite nanoparticles with antimicrobial potency. Mater Sci Energy Technol 2:15-21

13. Shameli K, Ahmad MB, Zamanian A et al (2012) Green biosynthesis of silver nanoparticles using Curcuma longa tuber powder. Int J Nanomed 7:5603-5610
14. Lukman Al, Gong B, Marjo CE, Roessner U et al (2011) Facile synthesis, stabilization, and anti-bacterial performance of discrete Ag nanoparticles using Medicago sativa seed exudates. J Colloid Interface Sci 353:433-444

15. Divya MJ, Sowmia C, Dhanya KP et al (2013) Screening of antioxidant, anticancer activity and phytochemicals in methanolic extract of Hibiscus rosa-sinensis leaf extract. Res J Pharmaceut Biol Chem Sci 4:1308-1316

16. Sugumaran M, Poornima M, Sethuvani S (2012) Phytochemical and trace element analysis of Hibiscus rosa sinensis Linn and Hibiscus syriacus Linn flowers. Nat Prod 8:341-345

17. Agu HO, Okoli NA (2014) Physico-chemical, sensory, and microbiological assessments of wheat-based biscuit improved with beniseed and unripe plantain. Food Sci Nutr 2:464-469

18. Sadasivam S, Manickam A (1997) Estimation of crude fibre. In: Sadasivam S, Manickam A (eds) Biochemical methods, 2nd edn. New Age International (P) Ltd., New Delhi, pp 20-21

19. Prasad C, Yuvaraja G, Venkateswarlu P (2017) Biogenic synthesis of $\mathrm{Fe}_{3} \mathrm{O}_{4}$ magnetic nanoparticles using Pisum sativum peels extract and its effect on magnetic and Methyl orange dye degradation studies. J Magnet Magnet Mater 424:376-381

20. Prasad C, Karlapudi S, Rao CN et al (2017) A highly resourceful magnetically separable magnetic nanoparticles from aqueous peel extract of Bottle gourds for organic dyes degradation. J Mol Liq 243:611-615

21. Venkateswarlu $S$, Natesh Kumar B, Prasad CH, Venkateswarlu $P_{\text {, }}$ Jyothi NVV (2014) Bio-inspired green synthesis of $\mathrm{Fe}_{3} \mathrm{O}_{4}$ spherical magnetic nanoparticles using Syzygium cumini seed extract. Phys B 449:67-71

22. Cornell RM, Schwertmann U (2003) The iron oxides, 2nd edn. Wiley, Weilhelm

23. Latha N, Gowri M (2014) Bio synthesis and characterisation of $\mathrm{Fe}_{3} \mathrm{O}_{4}$ nanoparticles using Caricaya Papaya leaves extract. Int J Sci Res 3:1551-1557

24. Rahman MM, Khan SB, Jamal A et al (2011) Iron oxide nanoparticles, nanomaterials. In: Rahman MM (ed) Nanomaterials. InTech Open, London. https://doi.org/10.5772/27698

25. Makarov VV, Makarova SS, Love AJ et al (2014) Biosynthesis of stable iron oxide nanoparticles in aqueous extracts of Hordeum vulgare and Rumex acetosa plants. Langmuir 30:5982-5988

26. Meyyappan A, Banu AS, Kurian GA (2014) One step synthesis of iron oxide nanoparticles via chemical and green route-an effective comparison. Int J Pharm Pharm Sci 7:70-74

27. Shojaee S, Shahr MM (2016) Green synthesis and characterization of iron oxide magnetic nanoparticles using Shanghai White tea (Camelia sinensis) aqueous extract. J Chem Pharm Res 8:138-143

28. http://rruff.info/magnetite/R061111

29. Fahlepy MR, Tiwow VA (2018) Characterization of magnetite $\left(\mathrm{Fe}_{3} \mathrm{O}_{4}\right)$ minerals from natural iron sand of Bonto Kanang Village Takalar for ink powder (toner) application. J Phys Conf Ser 997:012036

30. Langford Jl, Wilson AJC (1978) Scherrer after sixty years: a survey and some new results in the determination of crystallite size. J Appl Cryst 11:102-113

31. Kanmani P, Lim TS (2013) Synthesis and structural characterization of silver nanoparticles using bacterial exopolysaccharide and its antimicrobial activity against food and multidrug resistant pathogens. Process Biochem 48:1099-1106

32. Usman GO, Ameh UE, Alifa ON et al (2015) Proximate composition of biscuits produced from wheat flour and maize bran composite flour fortified with carrot extract. J Nutr Food Sci 5:395

33. Bala A, Gul K, Riar CS (2015) Functional and sensory properties of cookies prepared from wheat flour supplemented with cassava and water chestnut flours. Cogent Food Agric 1:1019815 
34. Adeola AA, Ohizua ER (2018) Physical, chemical, and sensory properties of biscuits prepared from flour blends of unripe cooking banana, pigeon pea, and sweet potato. Food Sci Nutr $6: 532-540$
Publisher's Note Springer Nature remains neutral with regard to jurisdictional claims in published maps and institutional affiliations. 